\title{
A mouse model of complete-crush transection spinal cord injury made by two operations
}

\author{
Chen $\mathrm{Li}^{1,2,3 \#}$, Xingfei Zhu ${ }^{1,2 \#}$, Chia-Ming Lee ${ }^{3}$, Zhourui $\mathrm{Wu}^{1,2}$, Liming Cheng ${ }^{1,2}$ \\ ${ }^{1}$ Division of Spine Surgery, Department of Orthopaedics, Tongji Hospital, Tongji University School of Medicine, Shanghai 200065, China; ${ }^{2}$ Key \\ Laboratory of Spine and Spinal cord Injury Repair and Regeneration, Tongji University, Ministry of Education, Shanghai 200065, China; ${ }^{3}$ Department \\ of Psychiatry and Biobehavioral Sciences, David Geffen School of Medicine, University of California Los Angeles, Los Angeles, CA, USA \\ Contributions: (I) Conception and design: C Li, Z Wu, L Cheng; (II) Administrative support: L Cheng; (III) Provision of study materials or patients: \\ C Li, Z Wu; (IV) Collection and assembly of data: CM Lee, X Zhu; (V) Data analysis and interpretation: All authors; (VI) Manuscript writing: All \\ authors; (VII) Final approval of manuscript: All authors. \\ \#These authors contributed equally to this work. \\ Correspondence to: Liming Cheng. Division of Spine Surgery, Department of Orthopaedics, Tongji Hospital, Tongji University School of Medicine, \\ Shanghai 200065, China. Email: limingcheng@tongji.edu.cn.
}

Background: More and more studies have focused on the treatment of spinal cord injury (SCI) by tissue engineering, but there is still no ideal animal model that can genuinely and objectively simulate the real pathological process in clinical practice. Also, given the increasing availability and use of genetically modified animals in basic science research, it has become essential to develop clinically related models for SCI for use in mice.

Methods: Forty-eight C57BL/6 mice were divided into three groups (injured/sham/uninjured). We determined the scar range made by the first crush injury by specimen observation, hematoxylin and eosin (HE) staining, and immunofluorescence staining. Transection to completely remove a $2-\mathrm{mm}$ spinal cord segment centered on the lesion core was completed 6 weeks after the first injury in injured groups, whereas the sham group only underwent re-exposure of the spinal cord without transection injury. The characteristics of this SCI model were fully ascertained by specimen observation, HE staining, immunofluorescence staining, and quantitative real-time polymerase chain reaction (qRT-PCR).

Results: No mice died after the first injury. Histopathological findings suggested a scar range of $2 \mathrm{~mm}$. After the second operation, 2 mice of the injured group and 1 mouse of the sham group died. The Basso Mouse Scale (BMS) score and motor evoked potential (MEP) results showed that the neurological function of mice did not recover. Immunostaining showed that there were no neurons or neurofilament residues in the lesion core 4 weeks after the second injury. Astrocytes encapsulated immune cells to form dense glial scars. Most immune cells were confined to the core of the lesion and formed fibrous scars with the fibroblasts. At the same time, there was considerable angiogenesis in the lesion core and around the injury. The results of qRT-PCR showed that Ptprc was highly expressed in the lesion core, while Gfap, nestin, Cnp, and Sv2b were highly expressed in the adjacent region. This suggests that the lesion core is a highly inflammatory zone, but there may be spontaneous neurogenesis adjacent to the lesion core.

Conclusions: The mouse crash-complete transection SCI model made by the two operations has good simulation, high feasibility, and high reproducibility; it will be a useful tool for pre-clinical testing of SCI treatment.

Keywords: Spinal cord injury (SCI); animal model; method of surgery; histopathology

Submitted Sep 09, 2019. Accepted for publication Jan 02, 2020.

doi: $10.21037 /$ atm.2020.01.58

View this article at: http://dx.doi.org/10.21037/atm.2020.01.58 


\section{Introduction}

Spinal cord injury (SCI) has always played an essential role in the field of traumatic spinal diseases because of its high incidence, high disability rate, and low recovery rate $(1,2)$. To date, the effective treatment and rehabilitation of SCI remains a difficult medical problem worldwide (3). According to recent statistics, the incidence of SCI in the world is 10.4-83/1 million (4). Serious consequences such as paralysis caused by SCI often impose substantial burdens on families and society (5). Therefore, the establishment of a standard and ideal animal model of SCI is a prerequisite for the experimental study of SCI.

In the past 10 years, significant progress has been made in the treatment of SCI by implanting stem cells and functional biological materials into injured sites, thus improving the micro-environment, activating endogenous neural stem cells, and promoting the regeneration of neurons and axons (6-9). However, most of these methods are based on acute SCI animal models, such as the sharp transection model $(10,11)$, compression injury model (12), crush injury model (13), complete transection injury model (9), and so on. These studies transplanted cells or biomaterials immediately after SCI, circumventing the effects of glial scars, and fibrous scars on nerve regeneration. However, in clinical work, because of the unpredictable prognosis caused by the limitation of existing diagnostic techniques (14), at the early stage of injury, in which scare materials has yet to form, most patients do not agree to the surgical transplantation of stem cells, biomaterials, or other treatments unless there is no improvement in long-term paralysis. Therefore, the removal of scar tissue is essential for the treatment of SCI. Establishing an appropriate animal model of scar tissue removal can accurately, realistically, and objectively simulate the real clinical treatment process in clinical practice.

In this study, we established a new model of SCI in mice, which completely simulates the clinical treatment course of SCI through second operation. We first made a crush injury model on the spinal cord of mice. Six weeks after injury, when the mice recovered to the chronic stage (15), the scar was removed by second surgical operation, and the mouse crash-complete transection SCI model was established. In this article, we first describe the crush model, which has been proven by behavioral scoring and electrophysiology to cause significant neurological deficits, and which exhibits limited natural recovery. Next, the excision range of injured spinal cord tissue was determined by hematoxylin and eosin (HE) staining and immunofluorescence staining in crush model. After that, the complete procedure of the second operation is described, including the subsequent behavioral score and electrophysiology, which proved the feasibility and repeatability of the second operation. Finally, we elucidate the histopathological changes and provide a detailed neuroregeneration-related gene assessment to illustrate that this model can be used to assess the effectiveness of the treatments of SCI, including those of stem cells and biomaterials transplantation. The mouse complete-crush transection SCI model presented here will be a useful tool for pre-clinical treatment evaluation.

\section{Methods}

\section{Animal surgery}

All experimental procedures were approved by and performed following the standards of the Animal Welfare Committees of Tongji University in Shanghai, China. Eightweek-old female C57bL/6 mice weighing between 18-20 g were used. All animal operations were performed under general anesthesia with inhalant isoflurane (2\%) delivered in an oxygen-enriched air using a dissecting microscope (Nikon, Tokyo, Japan), and rodent stereotaxic apparatus (David Kopf Instruments, Tujunga, CA, USA). The first operation proceeded as follows. Laminectomy was performed at T9 to expose the spinal cord. No. 5 Dumont forceps (Fine Science Tools, North Vancouver, Canada) fixed on stereotaxic apparatus were used to crush the spinal cord with persistent pressure for $3 \mathrm{~s}$. For the sham group in the first operation, only laminectomy was performed on the T9 lamina without subsequent crush injury. The second operation proceeded as follows. Six weeks after the first crush injury, the spinal cord was exposed again along the original incision, and followed by transection to completely remove a $2-\mathrm{mm}$ spinal cord segment centered on the lesion core. For the sham group, the second operation merely involved re-exposing the spinal cord of the crush-injured mice during the second operation without transection injury. Animals were monitored daily for infection, abnormal wound healing, or weight loss. The bladder of mice was squeezed to aid micturition once a day until the mice were executed.

\section{Open field test}

The Basso Mouse Scale (BMS) open field test was used to evaluate the motor function of the hind limbs in the mice. In a double-blinded manner, mice were evaluated once a 
week before and after injury by the same two observers who were not aware of the experimental conditions.

\section{Electrophysiology analysis}

Electrophysiological testing was performed for each group by using Keypoint II dual-channel evoked potential/ electromyography (Dantech) every week after the first injury and the fourth week after the second injury. All the animals were anesthetized by intramuscular (IM) injections of ketamine $(20 \mathrm{mg} / \mathrm{kg})$. Motor evoked potential (MEP) commonly relates to the action potential elicited by stimulation of the motor cortex. For MEP recording, 2 stimulating electrodes were included: the positive electrode was placed on the skull surface of motor area of cerebral cortex [antero-posterior $(\mathrm{AP}) \pm 1.0$, left/right \pm 1.5 , dorsoventral (DV) $0, \mathrm{~mm}$ from bregma], $1 \mathrm{~mm}$ behind the bregma, and $1.5 \mathrm{~mm}$ on the left or right side from the midline; and the negative electrode was placed on the skull $0.5 \mathrm{~cm}$ lateral to the positive electrode. The recording electrode was inserted into the left or right gastrocnemius muscle of the hind limbs at a depth of $1.5 \mathrm{~mm}$.

Moreover, the reference electrode was placed $2 \mathrm{~cm}$ away from the recording electrode, and the grounding line was placed in the middle of the stimulating electrode and the recording electrode. A 0-10 mA single square wave $(1 \mathrm{~Hz})$ was applied to stimulate the motor area of the cerebral cortex through the skull with a duration of $0.2 \mathrm{~ms}$. Two features of MEP were recorded at the gastrocnemius muscle of the hindlimb; i.e., peak-to-peak amplitudes were calculated as amplitude values and the onset time of the first response to the stimulus was measured as latency (16).

\section{Tissue processing}

After excessive inhalation of isoflurane, animals were transcardially perfused with $4 \%$ polyformaldehyde (PFA, Sigma, St. Louis, USA) and phosphate buffer saline (PBS, $\mathrm{pH}$ 7.4, Sigma). The spinal cord was removed and placed overnight in $4 \% \mathrm{PFA}$ at $4{ }^{\circ} \mathrm{C}$, then transferred to $30 \%$ sucrose (Sigma) twice and placed overnight at $4{ }^{\circ} \mathrm{C}$. The samples were photographed under a microscope (Nikon), then using tissue embedding media (Thermo Scientific, Waltham, MA, USA), a 1-cm spinal cord centered on the lesion core was encapsulated on dry ice. Tissue sections were cut at a thickness of $15 \mu \mathrm{m}$ using a frozen slicer (Leica, Wetzlar, Germany) and mounted on charged glass slides. The sections were stained by HE (Sigma) to see the histological structure of the lesional tissue.

\section{Immunobistochemistry}

Sections were washed 3 times with $1 \times$ PBS and then incubated with the primary antibodies at $4{ }^{\circ} \mathrm{C}$ overnight after $1 \mathrm{~h}$ blocking by $5 \%$ normal goat serum (NGS, Sigma) and $0.2 \%$ Triton X-100 (Sigma). The sections were then incubated at room temperature for $2 \mathrm{~h}$ with fluorescentlabeled secondary antibodies (Invitrogen, Waltham, MA, USA) and washed with $0.01 \mathrm{M}$ PBS 3 times before being observed under a confocal laser scanning microscope (Zeiss, LSM800). Fluorescence immunohistochemistry was performed using the following primary antibodies: rabbit anti-NeuN (Abcam, Cambridge, MA, USA; 1:500), chicken anti-microtubule-associated protein 2 (Map2) (Abcam, 1:500), rabbit anti-glial fibrillary acidic protein (Gfap) (Dako, St. Clara, CA, USA; 1:1,000), rat antiCd45 (eBioscience, Waltham, MA, USA; 1:500), purified anti-Neurofilament Marker (pan axonal, cocktail, SMI312) (Biolegend, San Diego, CA, USA; 1:1,000), mouse anti-fibronectin (Fn1) (Abcam, 1:200), rat anti-CD11b (eBioscience, 1:500), guinea pig anti-ionized calciumbinding adapter molecule 1 (IBA1) (Synaptic Systems, Goettingen, Germany; 1:800), rabbit anti-CD34 (Abcam, $1: 250)$.

\section{Image quantification}

For each group of experimental animals $(\mathrm{N} \geq 3)$, slices containing the central spinal canal were selected. The target areas ware photographed by a $20 \times$ objective lens without optical zoom by confocal laser scanning microscopy at a resolution of $1,024 \times 1,024$ pixels. Each region was scanned along the $\mathrm{z}$-axis at intervals of $1.5-2.5 \mu \mathrm{m}$. A final highdefinition $3 \mathrm{D}$ image was achieved via reconstructing these consecutive scans using Imaris software (Bitplane). We then used Imaris to count cells and signal areas in different regions. All figures were composed with Adobe Photoshop, Graphpad Prism, and Adobe Illustrator.

\section{Quantitative real-time polymerase chain reaction (qRT-PCR)}

Under isoflurane-induced anesthesia, the fresh spinal cord tissue of the target area was obtained under the microscope. Total RNA was isolated by TRIzol (Invitrogen) and purified by RNeasy Mini Kit (Invitrogen) according 
Table 1 Primer list for qRT-PCR

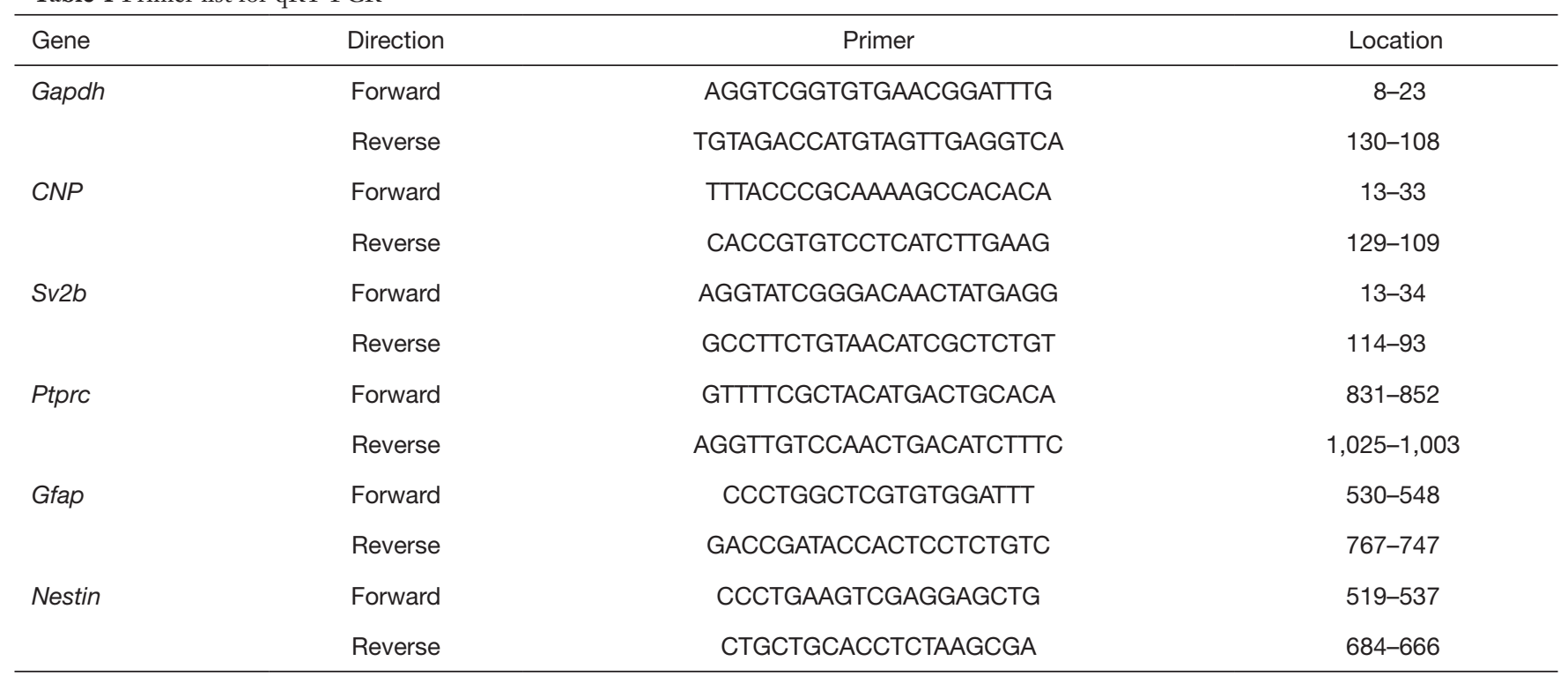

Ptprc, protein tyrosine phosphatase, receptor type C; Gfap, glial fibrillary acidic protein.

to the manufacturer's instructions. Total RNA was isolated by TRIzol and purified by RNeasy Mini Kit (Invitrogen) according to the manufacturer's instructions. PrimeScript RT kit (TAKARA) was used to produce the cDNA. Realtime PCR was performed using TAKARA SYBR Premix Ex TAQ (Tli RNaseH Plus) kit and ABI 7900 sequence detector (Applied Biosystems). The efficiency and specificity of each primer pair were examined by standard curves of the functions of continuously diluted cDNA and unchained curves, respectively. After normalization to the transcription level of the housekeeping gene GAPDH, the multiple changes were calculated based on the $2^{-\Delta \Delta C t}$ method. The sequence of primers used in qRT-PCR is shown in Table 1.

\section{Statistical analysis}

Graphpad Prism was used for statistics. The data were expressed as mean $( \pm \mathrm{SD})$. Student's $t$-test and unpaired Student's $t$-test were used to determine the statistical difference between the two groups. $\mathrm{P}<0.05$ was considered to indicate significant statistical differences.

\section{Results}

\section{A stable mouse T9 SCI crush model was established in the first operation}

We first established the mouse T9 SCI crush model, which proved stable and reliable by BMS, open-field test, and MEP recording. Eight-week-old C57BL/6 mice were subjected to SCI at T9 by crushing with a No. 5 Dumont forceps for $3 \mathrm{~s}$ (Figure 1A). First, we exposed the spine and located the T9 according to the shape of the spinous process. Then, we carefully removed the T9 lamina, which would not damage the spinal cord in the process. Finally, we used forceps to crush the spinal cord for $3 \mathrm{~s}$ to induce a linear lesion core (Figure 1B). The sham group only underwent laminectomy with no crush injury. Gross locomotion was assessed using the BMS open-field test before the injury and 1, 2, 3, 4, 5, and 6 weeks after injury (Figure 1C). The BMS score shows that the model is an incomplete injury model, like most clinical cases. The motor function of the mice recovered to $2-3$ points 2 weeks post-surgery, and then the score became stable. We later conducted MEP recording to assess the motor pathway and functional recovery. The amplitude values of MEP were the peak-to-peak amplitudes, and the time duration of onset to the stimulus response was measured as latency (Figure 1D). The MEP signal was not recorded immediately after the injury, so the latency was recorded as infinity $(\infty)$. As time progressed, the amplitude gradually increased, and the latency gradually decreased. Similar to the BMS score, the MEP results tended to stabilize after 2 weeks, indicating that the SCI entered the chronic phase 2 weeks after injury (Figure 1E). 
A

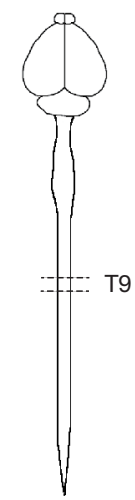

C

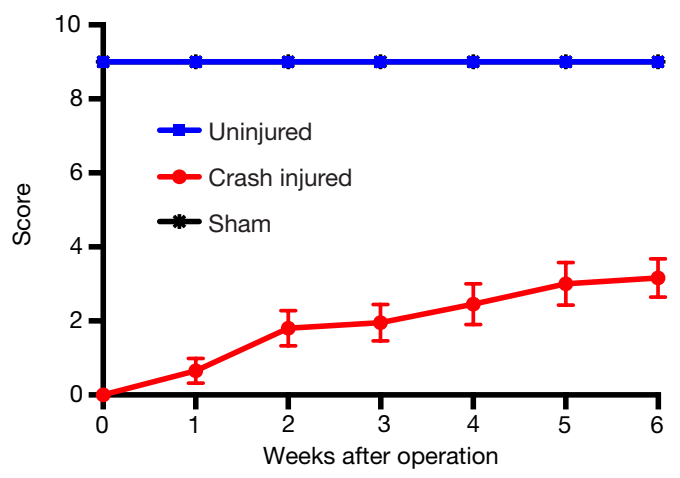

E

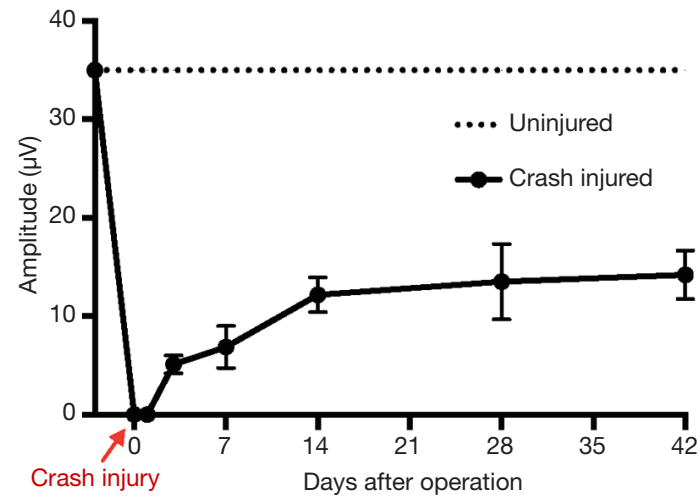

B

D
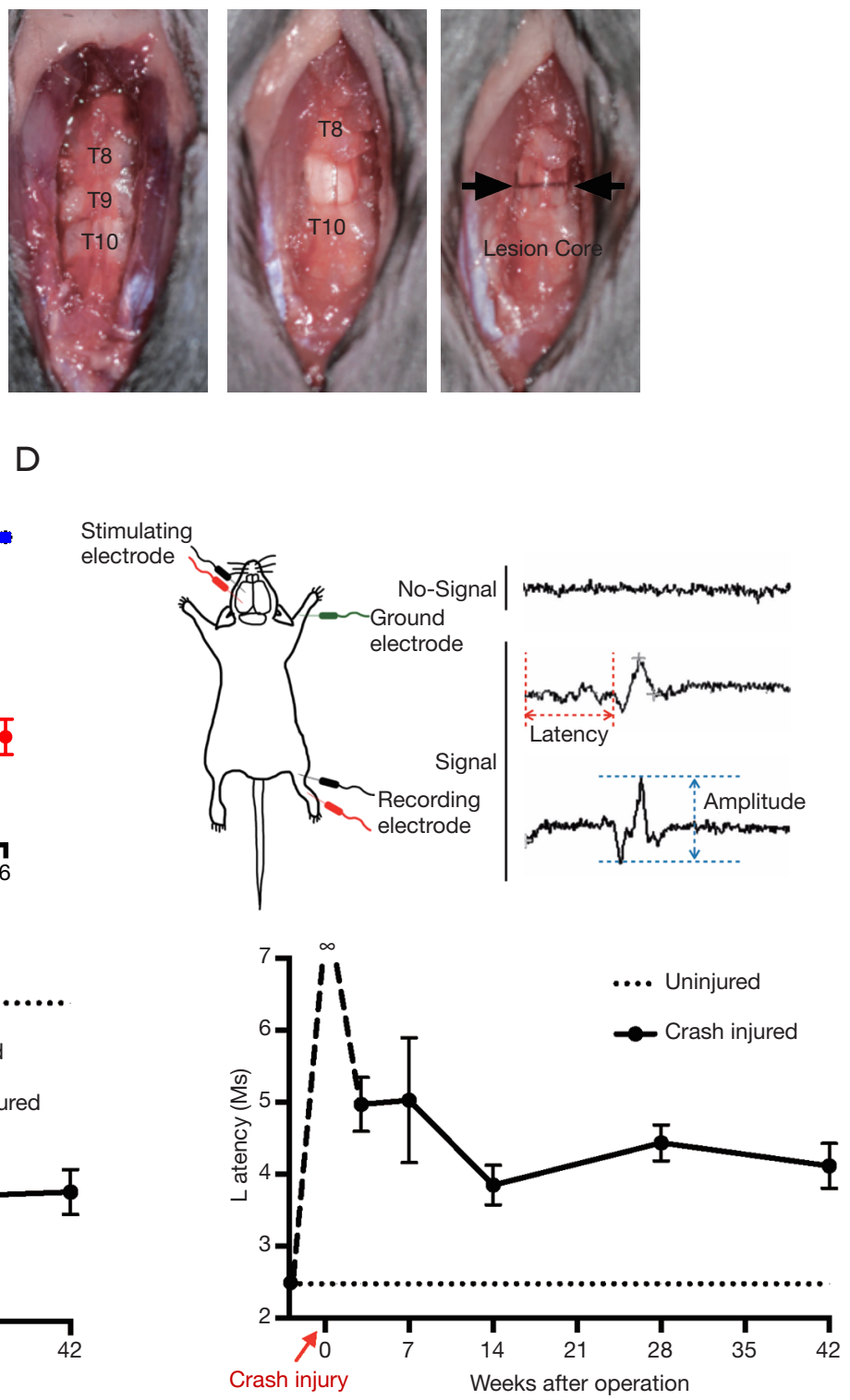

Figure 1 Establishing the T9 SCI crush model in the first operation. (A) Schematic illustration of anatomical positioning of the SCI and SCI crush model using a No. 5 Dumont forceps. (B) The first surgical procedure: expose the spine and determine T9 based on the shape of the spinous process (the left panel). Remove the T9 lamina and expose the spinal cord (the middle panel). Use forceps to crush the spinal cord and induce a linear lesion core (the right panel). (C) BMS open-field test showing hindlimb functional motor recovery until 6 weeks after SCI; the sham group underwent laminectomy only without crush (mean $\pm S D, n \geq 6$ ). (D) Schematic illustration of MEP recording and representative MEP traces. (E) MEP amplitude and latency change within 6 weeks of the operation (mean $\pm \mathrm{SD}, \mathrm{n} \geq 3$ ). T9, thoracic 9; $\infty$, infinity; SCI, spinal cord injury; BMS, Basso Mouse Scale; MEP, motor evoked potential.

\section{Removal of the 2-mm spinal cord segment centered on the lesion core during the second operation was based on the bistopathological changes of crush injury}

We observed the pathological changes of the spinal cord
6 weeks after crush injury by specimen observation, HE staining, and immunofluorescence staining to determine the length of the spinal cord segment removed during the second operation. Under the light dissecting microscopic, the lesion 
core was visible 1 day after the crush injury, and there was a large amount of hematoma around the lesion. Six weeks after crush injury, the hematoma was completely absorbed, and the lesion core had only one pale yellow scar that was difficult to discern (Figure 2A). HE staining showed that there was congestion near the lesion 1 day after the injury, and pathological changes such as cavities and demyelination began to appear. At 6 weeks after the injury, the congestion disappeared, and a lesion core composed of a large number of cells formed, with a cavity forming around it (Figure 2B). Immunofluorescence staining was used to quantitatively analyze the characteristics of the target area. We centered on the lesion core and divided the spinal cord photos into different regions every $0.5 \mathrm{~mm}$ (Figure 2C). Protein tyrosine phosphatase, receptor type C (Ptprc), also known as CD45, was used to label residential and infiltrated pan-immune cells to assess inflammation levels. Gfap was used first to label astrocytes and then to define glial scars by measuring astrocyte density. Our study found that astrocytes were activated in substantial amounts throughout the spinal cord 6 weeks after crush injury. Although the glial scar formed by astrocytes encapsulated a large number of inflammatory cells to form a lesion core which prevented the spread of inflammation, there were still a few diffuse infiltrations of inflammatory cells in the surrounding area of the lesion core (Figure 2D). In the region 10-15 $\mathrm{mm}$ away from the lesion core, the number of CD45-positive inflammatory cells and the astrocyte area were still significantly higher than the uninjured spinal cord (Figure 2E). Neurons are the basic functional units of the central nervous system, and NeuN is a neuronal nuclear antigen that is commonly used as a biomarker for neurons. Map2 is a specific marker of neuronal cell bodies and dendrites. Our immunofluorescence staining showed that 6 weeks after the crash injury, the closer to the lesion core, the fewer neurons there were, and no neuron survived in the lesion core (Figure 2F). Quantitative analysis of NeuN positive cells and Map2 positive areas showed that there was no significant difference between the lesion corecentered 10-15 mm area and the uninjured group (Figure 2G). Therefore, we decided to remove the $2 \mathrm{~mm}$ spine segment centered on the lesion core during the second operation.

\section{The SCI complete transection model was successfully established in the second operation}

We performed a second surgery on mice 6 weeks after the first crush injury. A 2-mm spinal segment centered on the lesion core was excised by complete transection in the second operation (Figure 3A). The suture knots left by the first operation could be seen when the skin was cut again along the wound. Non-absorbable sutures were used in the first operation to facilitate identifying the location of the second operation. The adhesive tissue was carefully separated layer by layer, completely exposing the injured spinal cord. A 2-mm spinal cord segment centered on the lesion core was then removed. The blade was scraped repeatedly along the ventral surface of the spinal canal, and any residual fibers in the lesion site were removed by aspiration. Finally, the muscles, fascia, and skin were closed layer by layer (Figure 3B). The second operation for the sham group only involved the spinal cord being reexposed, with no secondary injury. The BMS open-field locomotor test was continuously evaluated 6 weeks after the second operation. After the second operation, the hindlimb function decreased to 0 again, showing there was almost no recovery. In addition, there were significant differences between the injury group and the sham operation group (Figure 3C). Because the MEP signal could not be detected in the injured group, the latency was infinite. There was a significant difference in amplitude between the injured group and the non-injured group 4 weeks after the second operation (Figure 3D). After the second injury, the mice could survive for more than 3 months, which met the experimental requirements of SCI intervention, demonstrating that the model was successful.

\section{Immunostaining revealed pathological features of the spinal cord after the second operation}

We examined the gross anatomical changes in the lesion area 4 weeks after the second operation. Under the light dissecting microscopic, new scar-like tissue was seen anatomically "gluing" to both ends of the severed spinal cord together 4 weeks after the operation (Figure 4A). HE staining showed that the lesion core was filled with a large number of cells, and there were cavities in the core and adjacent tissues (Figure 4B). To understand the cellular structure of the lesion core and the tissue changes around the lesion, we performed immunofluorescence staining on various cell markers. Pan-neuronal markers NeuN and Map2 showed no $\mathrm{NeuN}^{+} / \mathrm{Map}^{+}$neurons in the lesion core. In the area outside the lesion core, the closer to the lesion core, the fewer the $\mathrm{NeuN}^{+} / \mathrm{Map}^{+}$neuronal entities, and the more fragmented the neuronal processes. In areas far from the lesion core, the number and shape of neurons were no different from those of the normal tissues (Figure 4C). 
A

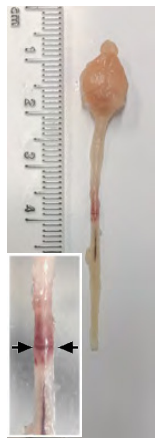

$1 \mathrm{~d}$

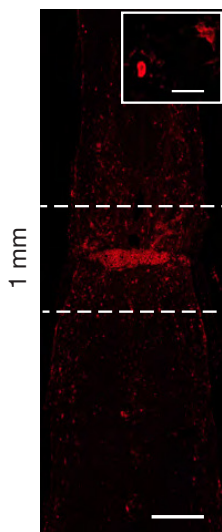

CD45

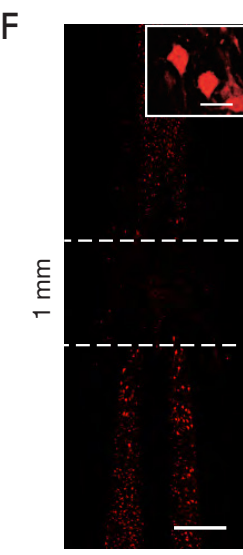

NeuN

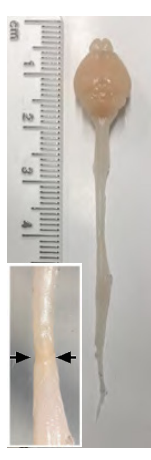

$6 \mathrm{w}$
B

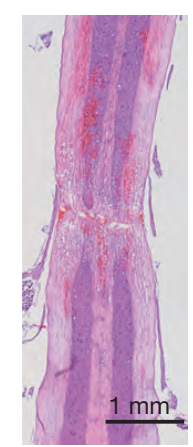

$1 \mathrm{~d}$

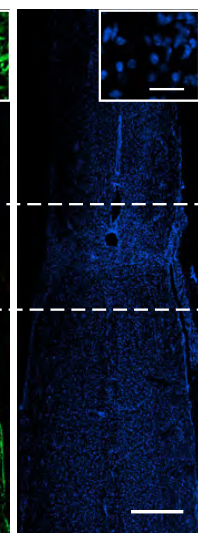

Dapi

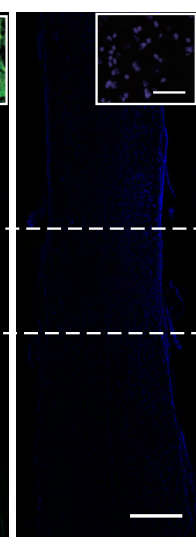

Dapi

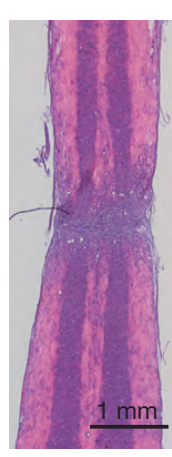

$6 \mathrm{w}$

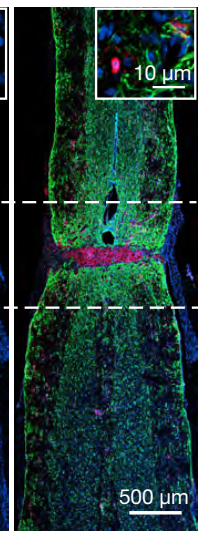

Merge

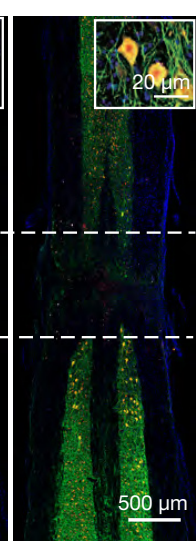

Merge

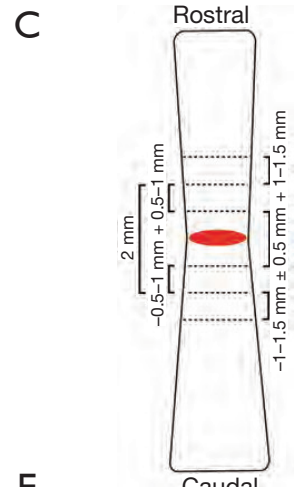

$\mathrm{E}$
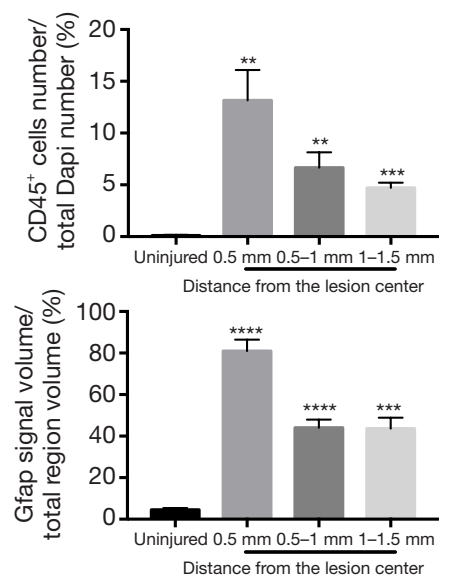

G
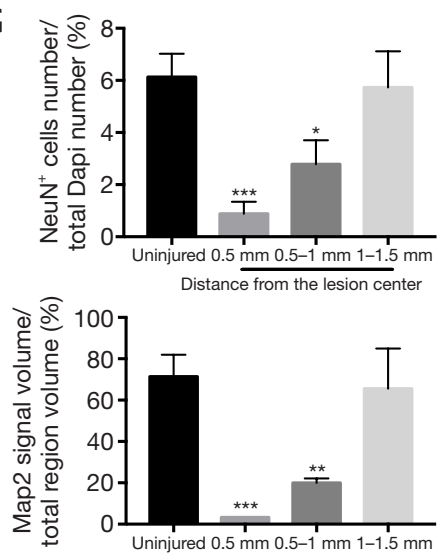

Figure 2 Histopathological changes determine the length of the spine segment removed during the second operation. (A) Dorsal view of representative spinal cords at 1 day and 6 weeks after the first operation. The black arrow shows the lesion core. (B) HE staining of spinal cord tissue at 1 day and 6 weeks after the first operation. (C) Schematic of quantitative analysis regions. (D) Immunostaining of the astrocyte marker Gfap and pan-leukocyte surface marker CD45 (Ptprc) at 6 weeks after the first operation. (E) Quantitative analysis of CD45-positive cells and Gfap signal volume in each region illustrated in $\mathrm{C}$ compared with the uninjured group. All regions of the injured group were significantly higher than the uninjured group in the number of CD45-positive cells. (mean $\pm \mathrm{SD}$; ${ }^{* *}, \mathrm{P}<0.01$; ${ }^{* * *}, \mathrm{P}<0.005$; ****, $\mathrm{P}<0.001$, $\mathrm{n}=6$, unpaired Student's $t$-test). (F) Immunofluorescence staining of neuronal makers Map2 and NeuN at 6 weeks after the first operation. (G) Quantitative analysis of NeuN positive cells and Map2 signal volume in each region illustrated in C compared with the uninjured group. There was no significant difference between the region $10-15 \mathrm{~mm}$ from the lesion core and the uninjured group (mean $\pm \mathrm{SD}$; *, $\mathrm{P}<0.05$; **, $\mathrm{P}<0.01$; ***, $\mathrm{P}<0.005, \mathrm{n}=6$, unpaired Student's $t$-test). HE, hematoxylin and eosin; Gfap, glial fibrillary acidic protein; Map2, microtubuleassociated protein $2 ; \mathrm{SD}$, standard deviation. 
A

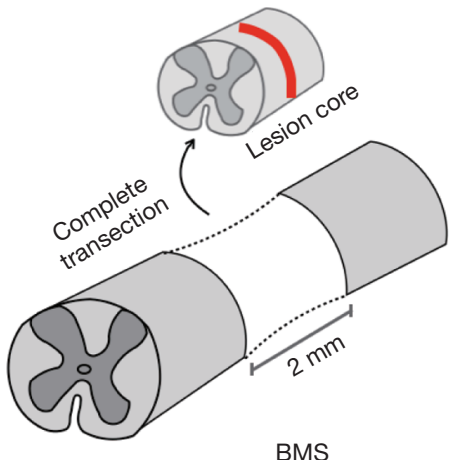

BMS
B

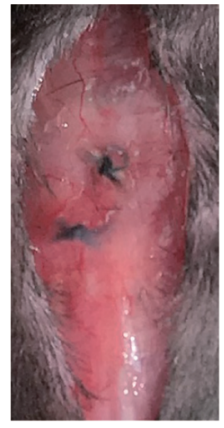

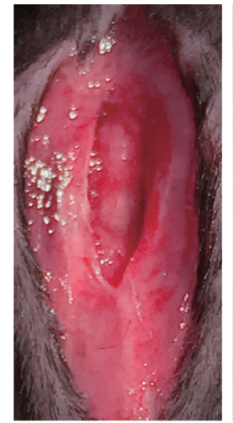

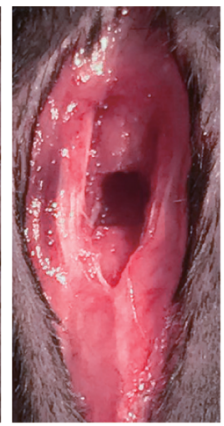

C
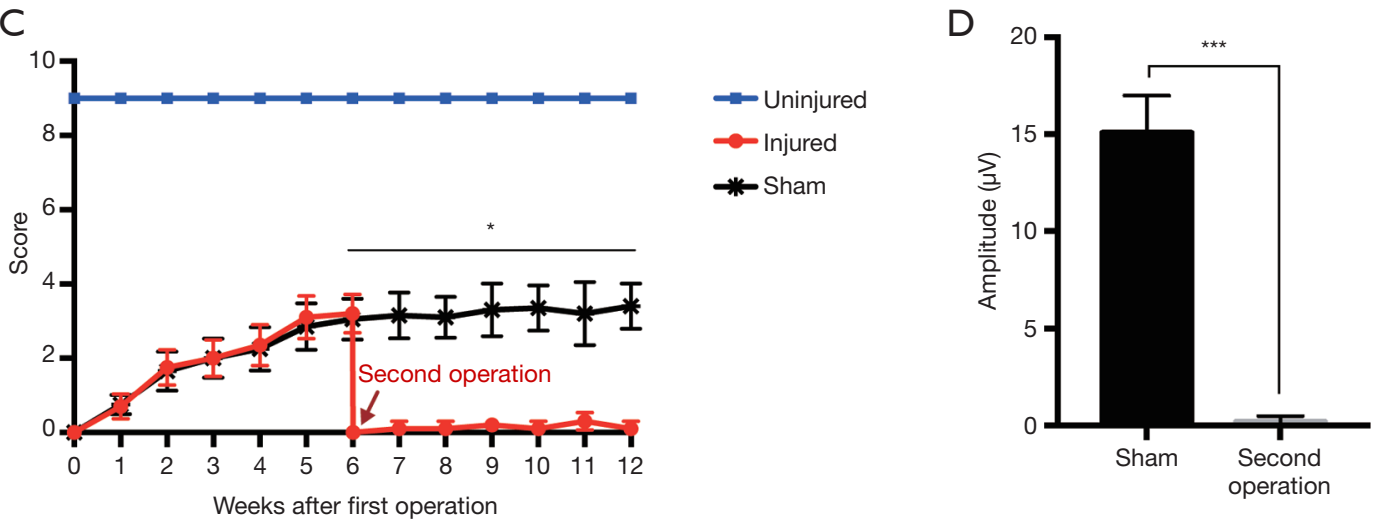

Figure 3 Establishing the complete SCI complete transection model in the second operation. (A) A schematic illustration of the complete SCI transection model by transection at the T9 level, with the removal of a 2-mm spinal cord segment centered on the lesion. (B) The second surgical procedure: 6 weeks after the first operation, cut the skin again along the wound (the left panel). Separate tissues layer-bylayer to expose the injured spinal cord (the middle panel). Completely remove the 2-mm spinal segment from the center of the lesion (the right panel). (C) BMS open-field test shows hindlimb motor functional change until 12 weeks after the first operation. After the second operation, the hindlimb function decreased again to 0 , and there was then no recovery. In the sham group, the spinal cord was re-exposed during the second operation without secondary injury (mean $\pm \mathrm{SD}$; * $, \mathrm{P}<0.05, \mathrm{n}=6$, unpaired Student's $t$-test with the comparison between the sham and second operation groups at each time point). (D) MEP amplitude analysis of sham and second operation groups 6 weeks after the second injury (mean $\pm \mathrm{SD}$; ${ }^{* *}, \mathrm{P}<0.005, \mathrm{n}=3$, unpaired Student's $t$-test). SCI, spinal cord injury; BMS, Basso Mouse Scale; MEP, motor evoked potential; SD, standard deviation.

SMI-312 can be widely used to label neuronal projections, including axons, and dendrites. Our images showed that in areas far from the lesion core, SMI-312 signals were densely reticulated in the gray matter and regularly linear in the white matter, which was the same as in normal tissues. Around the lesion core, the signal of SMI-312 was disordered, which may be related to axonal contracture and regeneration. However, the SMI-312 signal was not captured in the lesion core, showing that axons could not pass through scar tissue after injury (Figure 4D). In the same tissue section, we also stained Fn1 antibody and found that there were a large number of $\mathrm{Fn} 1^{+}$cells in and around the lesion core, but there were no $\mathrm{Fn} 1^{+}$cells in the distant area, which indicated that fibroblasts were an essential part of the lesion core scar tissue (Figure 4D). Four weeks after the second operation, astrocytes $\left(\mathrm{Gfap}^{+}\right)$encapsulated inflammatory cells $\left(\mathrm{CD} 45^{+}\right)$again, forming dense glial scars. Most inflammatory cells were confined to the core of the lesion, but there were still a few in the surrounding tissues, and the farther away they were, the fewer the number. The $\mathrm{Gfap}^{+}$cells surrounding the lesion core cross-linked to each other to form a dense network. In areas far from the lesion, these cells, although independent of each other, were still different in shape from the astrocytes in the normal spinal cord, exhibiting a certain polarity and appearing to migrate toward the lesion core (Figure 4E). The detection of 
A

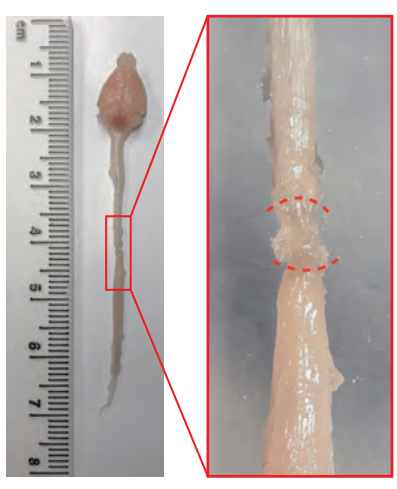

B

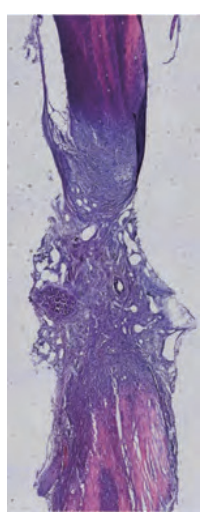

C

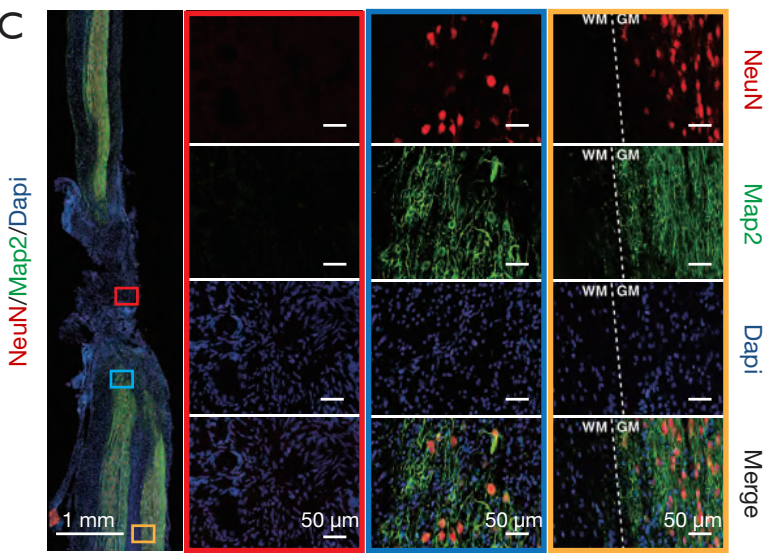

$\mathrm{E}$

D

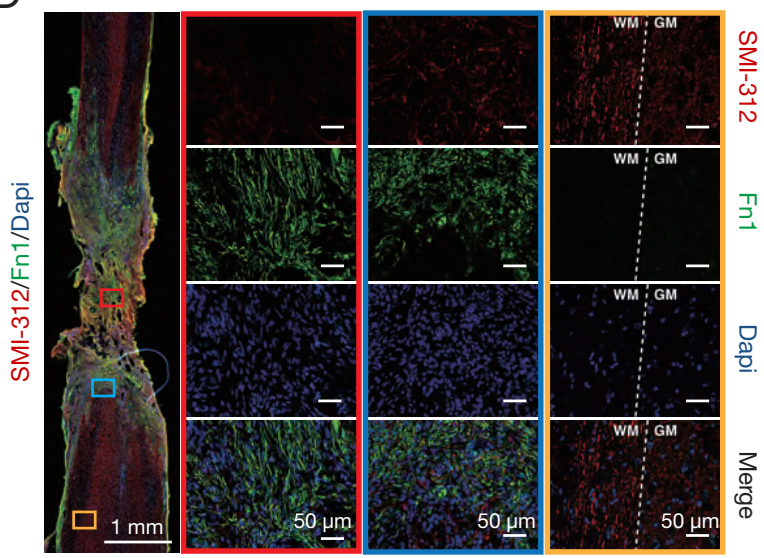

$\mathrm{F}$

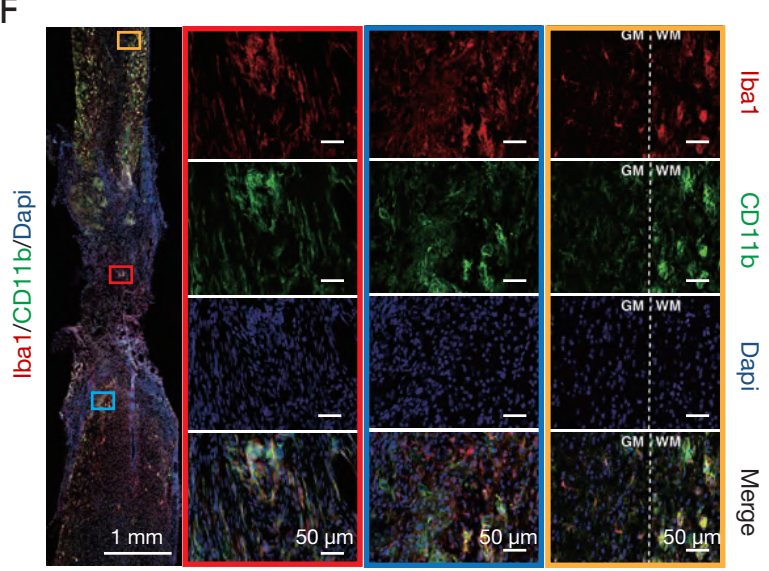

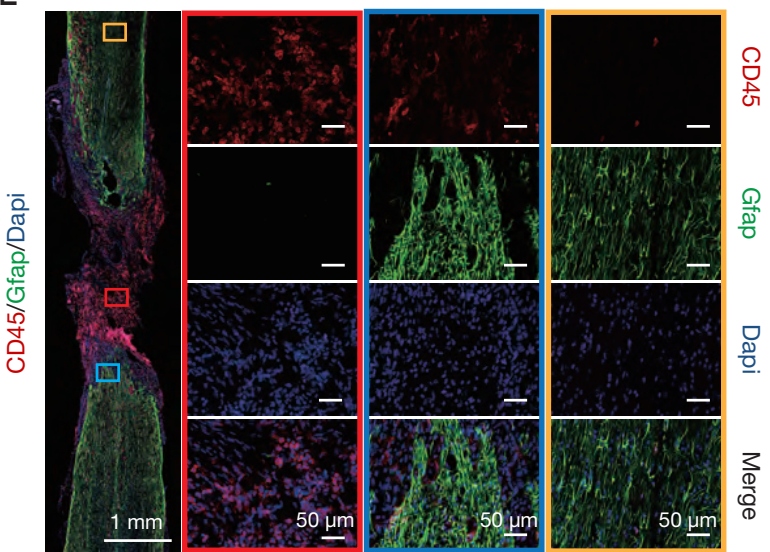

G

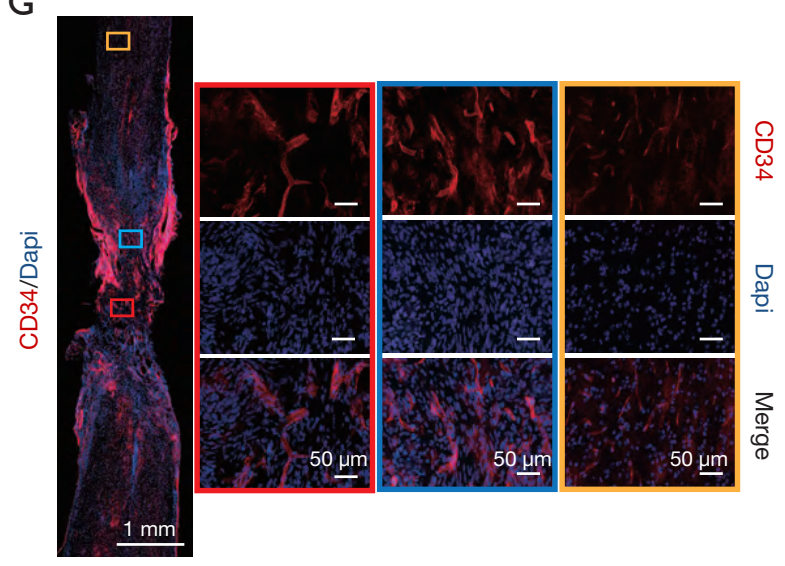

Figure 4 Immunostaining revealed pathological features of the spinal cord after the second operation. (A) Dorsal view of the representative spinal cords 4 weeks after the second operation. The newly generated scar tissue fills the spinal cord lesion region (in red brackets). (B) HE staining of spinal cord tissue 6 weeks after the second operation. (C,D,E,F,G) Immunofluorescence staining of the various cell markers 4 weeks after second operation. Magnified images of lesion area (red box), the peripheral area of the lesion (blue box), and away from the lesion area (yellow box) are shown on the right. (C) Neuronal makers Map2 and NeuN; (D) pan axonal marker SMI-312 (neurofilament) and fibroblast marker fibronectin (Fn1); (E) astrocyte marker Gfap and pan-leukocyte surface marker CD45 (Ptprc); (F) microglia markers Iba1 and CD11b; (G) vascular marker CD34. WM, white matter. GM, gray matter; HE, hematoxylin and eosin; Map2, microtubule-associated protein 2; Gfap, glial fibrillary acidic protein; Ptprc, protein tyrosine phosphatase, receptor type C. 
microglia/macrophages in the mouse spinal cord samples by allograft inflammatory factor 1 (AIF1), also known as IBA1 and CD11b, found that IBA1 and CD11b also participate in scar tissue composition. In the lesion core, $\mathrm{IBA}^{+} / \mathrm{CD} 11 \mathrm{~b}^{+}$ cells in the spinal cord became larger and rounder than those in the normal spinal cord. Microglia/macrophages in the mouse spinal cord samples were detected by IBA1 and CD11b, indicating that they also participated in the formation of scar tissue. However, $\mathrm{IBA}^{+} / \mathrm{CD} 11 \mathrm{~b}^{+}$cells in the lesion core became larger and rounder than those in the normal spinal cord. In areas far from the lesion core, these large round microglia/macrophages were still abundant in the white matter, but not in the gray matter (Figure 4F). We used CD34-antibody to label blood vessels. Images showed regeneration in a large number of blood vessels in and around the lesion core (Figure 4G). These pathological staining results showed that 4 weeks after the second operation, the lesion core consisting of inflammatory cells, fibroblasts, blood vessels, and necrotic tissues, was formed, connecting the two broken ends of the spinal cord.

\section{The difference in gene expression between lesion core and peripheral area indicates that the model has repair potential}

$\mathrm{M}$ region denotes the lesion core, and $\mathrm{R}$ and $\mathrm{C}$ region denote the $2-\mathrm{mm}$ regions of the rostral and caudal adjacent to the lesion core, respectively. We mixed the $\mathrm{R}$ and $C$ region samples and used $\mathrm{qRT}$-PCR to analyze the expression of Ptprc, Gfap, Nestin, 2',3'-cyclic-nucleotide 3'-phosphodiesterase (CNP, CNPase), and synaptic vesicle glycoprotein 2B (Sv2b) between the lesion core and adjacent area (Figure 5A). The expression levels of Ptprc (CD45) in the $\mathrm{R} / \mathrm{C}$ region were lower than in the $\mathrm{M}$ region, but still significantly higher than in normal samples (Figure $5 B$ ). As a neural stem cell marker, Gfap can be co-expressed with nestin (a recognized neural stem cell marker) in the same cell. Gfap and nestin are highly expressed in R/C regions, with their expression being the lowest in the $\mathrm{M}$ regions (Figure $5 C, D$ ). CNPase is a myelin-related gene, and $\mathrm{Sv} 2 \mathrm{~b}$ encodes a kind of the synaptic vesicle protein. The expression levels of these two genes in the R/C region were higher than in the $M$ region, but still significantly lower than in normal samples (Figure 5E,F). These results suggest that there may be spontaneous nerve regeneration in the area adjacent to the lesion core without intervention. The above qRT-PCR data were consistent with the immunofluorescence results, which further proves that the pathological changes of the model described here are correct.

\section{Discussion}

Because of its low cost, ease of care, and suitability for functional analysis techniques, rodents have become a convenient model for SCI research (17). In this study, we used mice to make an SCI model, with the main reason being that in addition to having the advantages of rats, mice, with the significant development of genetic engineering technology and molecular biology, have genetic traits that are incomparable to other animals $(18,19)$. The genetic characteristics of mice are also a powerful tool for the study of SCI repair mechanisms. Therefore, it is especially important to develop an SCI model in mice. However, mice are light in weight and have a small tissue structure, which makes surgery difficult. In this study, to establish a stable mouse model, we used microsurgical instruments under a high-power microscope to achieve surgical refinement and micro-invasiveness. The complete transection model of SCI is reproducible and simple to standardize (20). The main advantage of the complete transection model is that any regenerative effect can be attributed to exogenous treatment, which is unmatched by other models. As there are no spared axons in the lesion core, this model can boast high fidelity for interventions, pharmacology, or cytology, which require the promotion of axonal regeneration or reconnection using exogenous cell sources $(21,22)$. This kind of surgery enables one to follow the behavior of the lesion site in a more precise manner because the damage to the nerve fibers is not spread out like in other models (23). Although SCI models such as weight loss or contusion offer the possibility of varying degrees of severity and functional outcome, many groups exhibit spontaneous recovery and locomotor improvement in moderate injuries (24). These consequences can mask the potentially beneficial effects of exogenous strategies and therefore hinder this kind of treatment. Several studies have used this model to study the effects of different scaffolds, biomaterials, and stem cell combinations on axonal regeneration after injury; e.g., polymer scaffold with rat bone marrow stem cells $(9,25)$. However, these studies used a complete transection model of acute injury; i.e., implantation of materials at the same time as the first operation in experimental animals. No studies have reported secondary surgical treatment of SCI after scar formation. Compared with other models, the complete transfection model of SCI has the disadvantage 
A
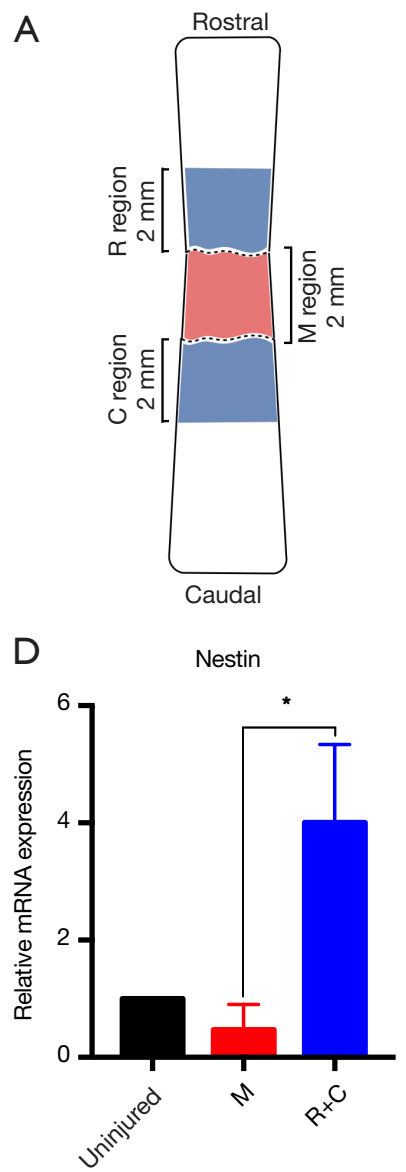

B

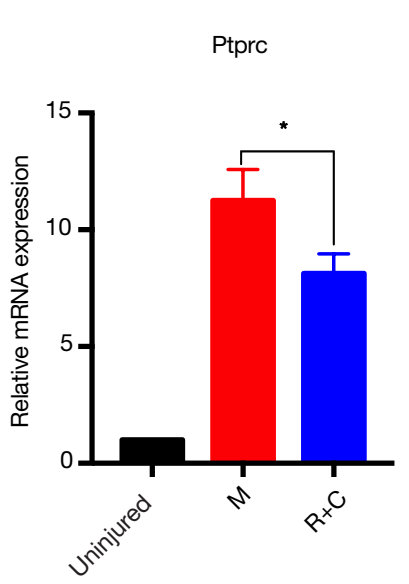

E

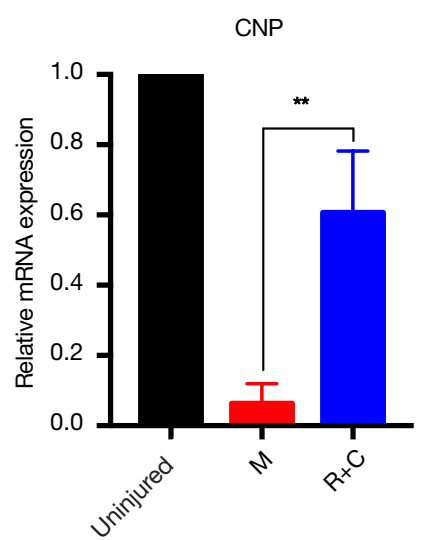

C

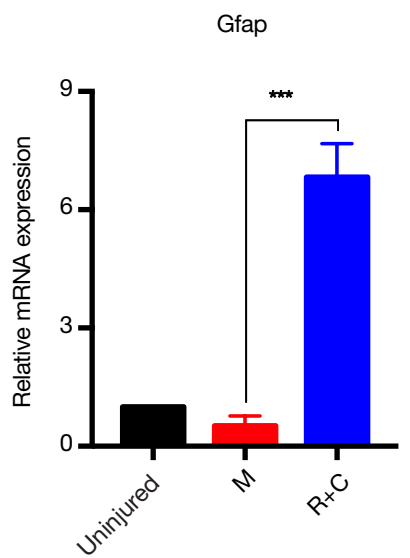

$\mathrm{F}$

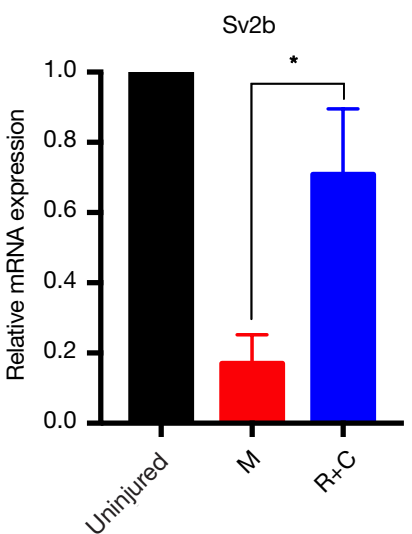

Figure 5 The difference in gene expression between the SCI lesion core and peripheral area. (A) Schematic of qRT-PCR areas. M region (red area) is the SCI lesion area, and the R/C region (blue areas) is a peripheral area of the lesion including the rostrum and caudal vertebrae. (B,C,D,E,F) qRT-PCR validation of expression of five genes in different regions in (A). (B) Inflammatory leukocyte-associated gene Ptprc (CD45) (mean $\pm \mathrm{SD}$; * $, \mathrm{P}<0.05, \mathrm{n}=6$, unpaired Student's $t$-test); (C) astrocyte/neural stem cell-related gene Gfap (mean $\pm \mathrm{SD}$; ${ }^{* * *}, \mathrm{P}<0.005$, $\mathrm{n}=6$, unpaired Student's $t$-test); (D) neuroectodermal stem cell-related gene nestin (mean $\pm \mathrm{SD} ;{ }^{*}, \mathrm{P}<0.05, \mathrm{n}=6$, unpaired Student's $t$-test); (E) myelin-associated gene $C N P$ (CNPase) (mean $\pm \mathrm{SD}$; **, $\mathrm{P}<0.01, \mathrm{n}=6$, unpaired Student's $t$-test); (F) synaptic-related gene $S v 2 b$ (mean $\pm \mathrm{SD}$; *, $\mathrm{P}<0.05, \mathrm{n}=6$, unpaired Student's $t$-test). SCI, spinal cord injury; Ptprc, protein tyrosine phosphatase, receptor type C; Gfap, glial fibrillary acidic protein; SD, standard deviation.

of a high degree of injury and slightly increased mortality in experimental animals (26). In our study, the disorder of the wound healing structure and tissue adhesion in the first operation caused substantial difficulty for the second surgery. Therefore, post-operative care such as that in pain relief, assisted urination, and nutrition enhancement, is very important.

In clinical cases, SCI is usually the result of sudden impact and sustained compression that occurs when the vertebrae of the spine are ruptured or dislocated (27). In the first surgery, the clamp injury method we chose not only maintained the integrity of the dura mater but also resembled the clinical crush injury caused by fracture displacement, disc herniation, etc. (28) to the spinal cord. In the first $24 \mathrm{~h}$ after injury, the hyper-acute stage of SCI is characterized by a large number of early stress reactions. From the third day to the seventh day, studies have found that inflammation and cell apoptosis gradually reach the peak value, which is the acute stage of SCI. From the first day to the week 2, which is the sub-acute stage, various pathological reactions gradually subside. Finally, 2 weeks after injury is considered to be the chronic stage because of 
the plateauing of animal behavioral and electrophysiological recovery, accompanied by stable gene changes at the transcriptional level $(22,29-32)$. The above changes are also consistent with our experimental results.

When SCI occurs, the local blood-brain barrier (BBB) is destroyed, causing leukocytes and macrophages to invade the nerve tissue of the injured area and secrete various cytokines and chemokines (33). This, along with fibrinogen and other substances in the blood infiltrating into the local area (34), cause local activation of astrocytes, cell hypertrophy, cell elongation and intertwining, and formation of new astrocytes and glial scars. Two weeks after SCI, mature glial scars have formed, wrapping fibrous scars with necrotic tissue and inflammatory cells (35). In addition to preventing inflammation from spreading to normal peripheral nerve tissues, mature glial scars repair the damaged BBB, stabilizing local micro-environment, and protecting peripheral nerve tissues $(35,36)$. At the same time, dense fibrous scars and glial scars act as physical barriers to prevent axon regeneration (37) and secrete chondroitin sulfate proteoglycans (CSPGs) and other substances that inhibit axon regeneration, while acting as chemical barriers to nerve regeneration $(38,39)$. In our study, this phenomenon was also observed. Therefore, the removal of fibrous scars while removing the glial scar is a prerequisite for the next step of tissue engineering in SCI treatment (40). Therefore, we chose to complete the second surgical resection of scar tissue 6 weeks after the first injury. At this time, the pathological process of SCI was in the chronic phase, and the scar tissue has completely formed (41). Wanner et al. made a detailed study of cell dynamics and cell-to-cell interactions during the formation of glial scars (35). Within a few hundred microns from the nearest fibrous scar, reactive astrocytes and their processes showed an elongated bipolar morphology, and their elongated processes intertwined to form a dense network structure. However, in spinal cord tissues more than $1 \mathrm{~mm}$ away from fibrous scars, reactive astrocytes showed a similarly normal astrocyte morphology. In our study, we found that there was no difference in the number and morphology of the neurons except astrocytes in the spinal cord tissues more than $1 \mathrm{~mm}$ away from the injured center. As a result, in the second operation, we chose to resect a total of $2-\mathrm{mm}$ spinal cord tissues with the clamp as the center. In order to accurately and completely remove chronic SCI tissue in clinical operation, and to avoid excessive resection of the normal spinal cord, it is very important to be able to conveniently define the glial scar. However, the method of histological staining has significant limitations in clinical cases. Recently, scholars have used diffusion tensor imaging (DTI) $(42,43)$, electrophysiology $(40)$, and other techniques to define scar boundaries.

In our study, the BMS score was used to assess the recovery of hind limb motor function in mice. It was found that the recovery of the hind limb was about 3 points 6 weeks after the first operation, which indicated that the injury caused by the first operation was incomplete, and this was in line with most clinical cases. After the second operation, the BMS score returned to 0 again (complete paralysis of both hind limbs). Motion evoked potentials could not be detected by electrophysiological methods, showing that all nerve tissues had been removed in the surgical area. The pathological staining results also confirmed that all nerve tissues were removed from the injured core, and no neurons and axons remained. This provides a good condition for the intervention and treatment of SCI $(6,9,40)$. After the second operation, a large number of astrocytes were activated, and dense glial scars were formed around the injured area (44). However, the morphology of astrocytes in different areas was quite different, suggesting that $\mathrm{Gfap}^{+}$astrocytes had heterogeneity, and there were different functional cell subsets $(19,45)$, which need further study. In addition to its expression in astrocytes, Gfap has also been reported to express Gfap in ependymal cells and neural progenitor cells, suggesting that some Gfap-positive cells may be neural stem cells $(46,47)$. Microglia are a special kind of immune cell of the nervous system which originate from the macrophage system. They phagocytize pathogens and damaged cells near injured areas, which can make their morphology significantly larger (48). The microglia in poliomyelitis that are far from the injury center are morphologically changed, while the microglia in white matter are the same as those in uninjured tissues. The reasons for this phenomenon are still not clear. In our study, we found that the lesion center was replaced by a large number of inflammatory cells, fibroblasts, angiogenesis, and other new tissues, to form fibrous scars, which is consistent with the pathological results of direct transection in previous studies $(35,49,50)$.

In our previous study, we analyzed the different spinal cord regions, including segment of the lesion site $(M)$, caudal vertebrae (C), and rostrum (R) $5-\mathrm{mm}$ to the lesion segment transcriptional profiles of the rat spinal cord complete transection model. Sample clustering showed that there was no significant difference between injuries adjacent to the rostra and caudal vertebrae, so 
the samples of $\mathrm{R}$ and $\mathrm{C}$ regions were mixed in this study. Weighted gene co-expression network analysis (WGCNA) analysis was performed on all sequenced samples, and we established ten co-expressing gene modules/clusters. Gene ontology (GO) analysis of these ten modules revealed several vital biological processes that occurred postinjury. Finally, the gene network analyses revealed potential key regulatory factors (hub genes, with the highest module membership and connectivity), which could potentially serve as targets to alter specific gene programs following SCI $(32,46)$. Through the above analysis, we screened out Ptprc (CD45), one of the hub genes of the immune response/inflammation-related module, while Gfap, nestin, Cnp, and Sv2b are the hub genes of the neurogenesis/ neurotransmission related module. Ptprc is a pan-leukocyte marker that can be used to assess the level of inflammation. Nestin is a well-known neural stem cell marker. In addition to expression in astrocytes, Gfap can also be co-expressed with nestin in reactive astrocytes (51), neural precursor cells, and ependymal cells $(46,47,52)$. Cnp is a myelinrelated gene and $\mathrm{Sv} 2 \mathrm{~b}$ encodes a kind of the synaptic vesicle protein. These genes are all associated with neurogenesis and neurological function. Therefore, we performed a qRTPCR validation on these hub genes in this SCI model. The expression of Ptprc in the lesion site was higher than that in the adjacent tissues, which was consistent with the results of immunofluorescence staining. It further proved that the lesion core is a high inflammatory reaction zone, and the microenvironment is not conducive to neurogenesis and axonogenesis. Gfap, nestin, Cnp, and Sv2b were more expressed in the adjacent regions than in the lesion core. This result indicates that although nerve regeneration occurred around the lesion site, there was also high inflammation, glial scars, and fibrous scars, which prevented the new nerve/axon from passing through the lesion core to form a functional neural network $(30,32)$. These results are entirely consistent with the complete transection model, indicating that our secondary surgery model has the same potential for neurogenesis/axonogenesis as the acute injury model and is suitable for the biomaterial/stem cell transplantation therapy of SCI research. These results also suggest that the inhibition of immunity to improve the microenvironment of the lesion region and promote nerve regeneration may be an effective method for the treatment of SCI.

\section{Conclusions}

In conclusion, this study demonstrates that the SCI model of complete scar excision by second operation in mice has good simulation, high feasibility, and high reproducibility, and it will be a useful tool for pre-clinical testing in SCI treatment.

\section{Acknowledgments}

Funding: This work was supported by grants from the State Key Program of the National Natural Science Foundation of China (No. 81330030) and the National Key Research and Development Program of China (No. 2016YFA0100800).

\section{Footnote}

Conflicts of Interest: The authors have no conflicts of interest to declare.

Ethical Statement: The authors are accountable for all aspects of the work in ensuring that questions related to the accuracy or integrity of any part of the work are appropriately investigated and resolved. All experimental procedures were approved by and performed following the standards of the Animal Welfare Committees of Tongji University in Shanghai, China [No. 2017-DW-(020)].

Open Access Statement: This is an Open Access article distributed in accordance with the Creative Commons Attribution-NonCommercial-NoDerivs 4.0 International License (CC BY-NC-ND 4.0), which permits the noncommercial replication and distribution of the article with the strict proviso that no changes or edits are made and the original work is properly cited (including links to both the formal publication through the relevant DOI and the license). See: https://creativecommons.org/licenses/by-nc-nd/4.0/.

\section{References}

1. David J Thurman; National Center for Injury Prevention and Control (U.S.). Guidelines for surveillance of central nervous system injury. Atlanta, GA: U.S. Department of Health and Human Services, Public Health Service: Centers for Disease Control and Prevention, National Center for Injury Prevention and Control, 1995.

2. Anwar MA, Al Shehabi TS, Eid AH. Inflammogenesis of Secondary Spinal Cord Injury. Front Cell Neurosci 2016;10:98.

3. Shende P, Subedi M. Pathophysiology, mechanisms and 
applications of mesenchymal stem cells for the treatment of spinal cord injury. Biomed Pharmacother 2017;91:693-706.

4. van Middendorp JJ, Hosman AJ, Donders AR, et al. A clinical prediction rule for ambulation outcomes after traumatic spinal cord injury: a longitudinal cohort study. Lancet 2011;377:1004-10.

5. Nikbakht-Nasrabadi A, Mohammadi N, Yazdanshenas M, et al. Toward overcoming physical disability in spinal cord injury: a qualitative inquiry of the experiences of injured individuals and their families. BMC Neurol 2019;19:171.

6. Itosaka H, Kuroda S, Shichinohe H, et al. Fibrin matrix provides a suitable scaffold for bone marrow stromal cells transplanted into injured spinal cord: a novel material for CNS tissue engineering. Neuropathology 2009;29:248-57.

7. Ronaghi M, Erceg S, Moreno-Manzano V, et al. Challenges of stem cell therapy for spinal cord injury: human embryonic stem cells, endogenous neural stem cells, or induced pluripotent stem cells? Stem Cells 2010;28:93-9.

8. Assinck P, Duncan GJ, Hilton BJ, et al. Cell transplantation therapy for spinal cord injury. Nat Neurosci 2017;20:637-47.

9. Yang Z, Zhang A, Duan H, et al. NT3-chitosan elicits robust endogenous neurogenesis to enable functional recovery after spinal cord injury. Proc Natl Acad Sci U S A 2015;112:13354-9.

10. López-Dolado E, Lucas-Osma AM, Collazos-Castro JE. Dynamic motor compensations with permanent, focal loss of forelimb force after cervical spinal cord injury. J Neurotrauma 2013;30:191-210.

11. Blanco JE, Anderson KD, Steward O. Recovery of forepaw gripping ability and reorganization of cortical motor control following cervical spinal cord injuries in mice. Exp Neurol 2007;203:333-48.

12. Moonen G, Satkunendrarajah K, Wilcox JT, et al. A New Acute Impact-Compression Lumbar Spinal Cord Injury Model in the Rodent. J Neurotrauma 2016;33:278-89.

13. Anderson MA, Burda JE, Ren Y, et al. Astrocyte scar formation aids central nervous system axon regeneration. Nature 2016;532:195-200.

14. Norenberg MD, Smith J, Marcillo A. The pathology of human spinal cord injury: defining the problems. J Neurotrauma 2004;21:429-40.

15. Kjell J, Olson L. Rat models of spinal cord injury: from pathology to potential therapies. Dis Model Mech 2016;9:1125-37.

16. Nardone R, Höller Y, Thomschewski A, et al. Assessment of corticospinal excitability after traumatic spinal cord injury using MEP recruitment curves: a preliminary TMS study. Spinal Cord 2015;53:534-8.

17. Cheriyan T, Ryan DJ, Weinreb JH, et al. Spinal cord injury models: a review. Spinal Cord 2014;52:588-95.

18. Kos CH. Methods in Nutrition Science: Cre/loxP System for Generating Tissue-specific Knockout Mouse Models. Nutr Rev 2004;62:243-6.

19. Meletis K, Barnabé-Heider F, Carlén M, et al. Spinal cord injury reveals multilineage differentiation of ependymal cells. PLoS Biol 2008;6:e182.

20. Lukovic D, Moreno-Manzano V, Lopez-Mocholi E, et al. Complete rat spinal cord transection as a faithful model of spinal cord injury for translational cell transplantation. Sci Rep 2015;5:9640.

21. Erceg S, Ronaghi M, Oria $M$, et al. Transplanted oligodendrocytes and motoneuron progenitors generated from human embryonic stem cells promote locomotor recovery after spinal cord transection. Stem Cells 2010;28:1541-9.

22. Blight AR. Spinal cord injury models: neurophysiology. J Neurotrauma 1992;9:147-9; discussion 149-50.

23. Jendelová P, Herynek V, Urdzíková L, et al. Magnetic resonance tracking of transplanted bone marrow and embryonic stem cells labeled by iron oxide nanoparticles in rat brain and spinal cord. J Neurosci Res 2004;76:232-43.

24. Moreno-Manzano V, Rodríguez-Jiménez FJ, García-Roselló $\mathrm{M}$, et al. Activated spinal cord ependymal stem cells rescue neurological function. Stem Cells 2009;27:733-43.

25. Kang KN, Lee JY, Kim DY, et al. Regeneration of completely transected spinal cord using scaffold of poly(D,L-lactide-co-glycolide)/small intestinal submucosa seeded with rat bone marrow stem cells. Tissue Eng Part A 2011;17:2143-52.

26. Talac R, Friedman JA, Moore MJ, et al. Animal models of spinal cord injury for evaluation of tissue engineering treatment strategies. Biomaterials 2004;25:1505-10.

27. McDonald JW, Sadowsky C. Spinal-cord injury. Lancet 2002;359:417-25.

28. Plemel JR, Duncan G, Chen KW, et al. A graded forceps crush spinal cord injury model in mice. J Neurotrauma 2008;25:350-70.

29. Hesp ZC, Goldstein EZ, Miranda CJ, et al. Chronic oligodendrogenesis and remyelination after spinal cord injury in mice and rats. J Neurosci 2015;35:1274-90.

30. Duan H, Ge W, Zhang A, et al. Transcriptome analyses reveal molecular mechanisms underlying functional recovery after spinal cord injury. Proc Natl Acad Sci U S A 2015;112:13360-5.

31. Rust R, Kaiser J. Insights into the Dual Role of 
Inflammation after Spinal Cord Injury. J Neurosci 2017;37:4658-60.

32. Luo D, Ge $W, \mathrm{Hu} X$, et al. Unbiased transcriptomic analyses reveal distinct effects of immune deficiency in CNS function with and without injury. Protein Cell 2019; 10:566-82.

33. Donnelly DJ, Popovich PG. Inflammation and its role in neuroprotection, axonal regeneration and functional recovery after spinal cord injury. Exp Neurol 2008;209:378-88.

34. Ryu JK, Davalos D, Akassoglou K. Fibrinogen signal transduction in the nervous system. J Thromb Haemost 2009;7 Suppl 1:151-4.

35. Wanner IB, Anderson MA, Song B, et al. Glial scar borders are formed by newly proliferated, elongated astrocytes that interact to corral inflammatory and fibrotic cells via STAT3-dependent mechanisms after spinal cord injury. J Neurosci 2013;33:12870-86.

36. Harris LJ, Zhang P, Abdollahi H, et al. Availability of adipose-derived stem cells in patients undergoing vascular surgical procedures. J Surg Res 2010;163:e105-12.

37. Sofroniew MV. Molecular dissection of reactive astrogliosis and glial scar formation. Trends Neurosci 2009;32:638-47.

38. Rhodes KE, Fawcett JW. Chondroitin sulphate proteoglycans: preventing plasticity or protecting the CNS?. J Anat 2004;204:33-48

39. Tang X, Davies JE, Davies SJ. Changes in distribution, cell associations, and protein expression levels of NG2, neurocan, phosphacan, brevican, versican V2, and tenascin-C during acute to chronic maturation of spinal cord scar tissue. J Neurosci Res 2003;71:427-44.

40. Xiao Z, Tang F, Tang J, et al. One-year clinical study of NeuroRegen scaffold implantation following scar resection in complete chronic spinal cord injury patients. Sci China Life Sci 2016;59:647-55.

41. Kawano H, Kimura-Kuroda J, Komuta Y, et al. Role of the lesion scar in the response to damage and repair of the central nervous system. Cell Tissue Res 2012;349:169-80.
42. Schwartz ED, Duda J, Shumsky JS, et al. Spinal cord diffusion tensor imaging and fiber tracking can identify white matter tract disruption and glial scar orientation following lateral funiculotomy. J Neurotrauma 2005;22:1388-98.

43. Rao JS, Zhao C, Zhang A, et al. NT3-chitosan enables de novo regeneration and functional recovery in monkeys after spinal cord injury. Proc Natl Acad Sci U S A 2018;115:E5595-604.

44. White RE, Mc'Tigue DM, Jakeman LB. Regional heterogeneity in astrocyte responses following contusive spinal cord injury in mice. J Comp Neurol 2010;518:1370-90.

45. Barnabé-Heider F, Göritz C, Sabelström H, et al. Origin of new glial cells in intact and injured adult spinal cord. Cell Stem Cell 2010;7:470-82.

46. Luo Y, Coskun V, Liang A, et al. Single-cell transcriptome analyses reveal signals to activate dormant neural stem cells. Cell 2015;161:1175-86.

47. Coskun V, Wu H, Blanchi B, et al. CD133+ neural stem cells in the ependyma of mammalian postnatal forebrain. Proc Natl Acad Sci U S A 2008;105:1026-31.

48. Bellver-Landete V, Bretheau F, Mailhot B, et al. Microglia are an essential component of the neuroprotective scar that forms after spinal cord injury. Nat Commun 2019;10:518.

49. Göritz C, Dias DO, Tomilin N, et al. A pericyte origin of spinal cord scar tissue. Science 2011;333:238-42.

50. Soderblom C, Luo X, Blumenthal E, et al. Perivascular fibroblasts form the fibrotic scar after contusive spinal cord injury. J Neurosci 2013;33:13882-7.

51. Pekny M, Wilhelmsson U, Tatlisumak T, et al. Astrocyte activation and reactive gliosis-A new target in stroke? Neurosci Lett 2019;689:45-55.

52. Frisén J, Johansson CB, Török C, et al. Rapid, widespread, and longlasting induction of nestin contributes to the generation of glial scar tissue after CNS injury. J Cell Biol 1995;131:453-64.
Cite this article as: $\mathrm{Li} \mathrm{C,} \mathrm{Zhu} \mathrm{X,} \mathrm{Lee} \mathrm{CM,} \mathrm{Wu} \mathrm{Z,} \mathrm{Cheng} \mathrm{L.} \mathrm{A}$ mouse model of complete-crush transection spinal cord injury made by two operations. Ann Transl Med 2020;8(5):210. doi: 10.21037/atm.2020.01.58 